\title{
Respect, Punishment and Mandatory Neurointerventions
}

\author{
Holmen, Sebastian Jon
}

\section{Published in:}

Neuroethics

DOI:

10.1007/s12152-020-09434-8

\section{Publication date:}

2021

\section{Document Version}

Peer reviewed version

Citation for published version (APA):

Holmen, S. J. (2021). Respect, Punishment and Mandatory Neurointerventions. Neuroethics, 14(2), 167-176. https://doi.org/10.1007/s12152-020-09434-8

\section{General rights}

Copyright and moral rights for the publications made accessible in the public portal are retained by the authors and/or other copyright owners and it is a condition of accessing publications that users recognise and abide by the legal requirements associated with these rights.

- Users may download and print one copy of any publication from the public portal for the purpose of private study or research.

- You may not further distribute the material or use it for any profit-making activity or commercial gain.

- You may freely distribute the URL identifying the publication in the public portal.

\section{Take down policy}

If you believe that this document breaches copyright please contact rucforsk@kb.dk providing details, and we will remove access to the work immediately and investigate your claim. 
This is a post-print version of: S.J. Holmen. 2020. Respect, Punishment and Mandatory Neurointerventions.

Neuroethics, forthcoming. https://doi.org/10.1007/s12152-020-09434-8

\title{
Respect, Punishment and Mandatory Neurointerventions
}

Sebastian Jon Holmen, RUC.

\begin{abstract}
The idea that acting morally is ultimately a question of treating others with respect has had a profound influence on moral and legal philosophy. Not surprisingly, then, some scholars forcefully argue that the modes of punishment that the states mete out to offenders should not be disrespectful, and, furthermore, it has been argued that obliging offenders to receive neurological treatment is incompatible with showing them their due respect. In this paper, I examine three contemporary accounts of what showing respect for offenders in our sentencing practices would amount to: that it involves not interfering with offenders' capacities for rationality and autonomy, that it should not undermine offenders' prospect of reform, and that it amounts to treating offenders as if opaque. I then critically discuss whether any of these accounts plausibly imply that mandating neurointerventions to some offenders is necessarily morally wrong. I argue that they do not.
\end{abstract}

\section{Introduction}

In some states in the US, sexual offenders are sometimes obliged by courts to be chemically castrated [1]. And in the UK offenders have been sentenced to receive methadone treatment in order to curb their opioid addiction [2]. In the near future the use of other such mandatory neurointerventions ${ }^{1}$ for similar crime-preventive purposes may also become scientifically tenable (for an overview, see [3]). For

\footnotetext{
${ }^{1}$ I understand mandatory neurointerventions as interventions mandated by the state as, or as part of, a criminal sanction that exerts their effect(s) directly on the recipient's brain.
} 
instance, it is possible that administering selective serotonin re-uptake inhibitors (SSRIs) to individuals with a history of aggression [4] may prove an aid in reducing recidivism among some groups of offenders by raising the low levels of the neurotransmitter serotonin associated with heightened levels of aggression and antisocial behaviour [5]. And, while it remains speculative, more or less invasive techniques for electromagnetic brain stimulation to, for instance, alter moral cognition [6, 7], reduce aggressive and impulsive behaviour [8,9] or curb drug addiction [10] might plausibly also prove to have a positive effect on reconviction rates. Arguably, if these or similar techniques are developed that, in a safe and effective manner, can reduce re-conviction rates among some groups of offenders then there are several good moral reasons for employing them. For example, this could reduce the harm that the future victims of repeat offenders would otherwise have to endure, and at the same time offenders would be spared the deprivations of future punishment. Furthermore, if the neurointerventions are indeed successful in bringing down reconviction rates this would mean that the current cost to societies posed by repeat offenders is also brought down (in the UK, for instance, the annual cost of reoffending by individuals who have previously received a custodial sentence is estimated to be around six billion pounds ([11], p. 17)). And these resources could then be used on initiatives that strive to ensure that individuals do not (need to) commit crimes in the first place or, alternative, they could be used to pursue other morally important goals. However, even if this is all true there may be other weightier moral concerns that rule out mandating neurointerventions to offenders. It is, for example, debated whether mandatory neurointerventions are affront to individuals' right to bodily integrity [12-14] and/or to mental self-determination [15-17]. But while these are surely important concerns they will not be confronted in this paper. Instead, I will consider variations of another less commonly debated moral concern about mandatory neurointervention in criminal justice: that such interventions show inadequate respect for offenders, and are consequently morally wrong to employ. The paper proceeds as follows. In section 2, I flesh out the central claim, features and scope of disrespect accounts of the wrongness of mandating neurointerventions, as well as point out points of divergence. In sections 3-5, 
it is critically discussed whether three variations of the disrespect account persuasively rule out the use of mandatory neurointerventions. I argue that they do not. Finally, section 6 summarises and concludes.

\section{Disrespect accounts of the wrongness of mandating neurointerventions}

The idea that acting morally essentially involves treating other persons (and oneself) with due respect, is one that has a firm standing among moral and legal philosophers [18]. Roughly, from this view morally right actions are the ones that show appropriate respect and, in contrast, actions that somehow show disrespect are morally wrong to perform. It is thus not surprising that some scholars have argued that it is morally wrong to employ a mode of punishment if it disrespects offenders. Moreover, and as will be clear, some also argue that mandating neurological interventions is disrespectful and thus wrong for the same reason. ${ }^{2}$ What we shall term disrespect accounts of the wrongness of mandating neurointerventions (or disrespect accounts for short) thus stipulate that:

Mandating neurointerventions as a response to wrongdoing is morally wrong since it involves disrespecting offenders, and it is morally wrong to disrespect persons.

In order to assess this claim more, of course, needs to be said about what more precisely it might mean that a mode of punishment disrespects offenders. And furthermore, why such considerations of respect imply that the use of mandatory neurointerventions would be morally objectionable. Although they have, as will be clear, quite different views on what treating offenders with respect ultimately amount to

\footnotetext{
${ }^{2}$ As might be clear, I am going to assume that respect-constraints on punishment should be understood to also apply to non-punitive measures, such as rehabilitative measures, that a state may pursue in the name of criminal justice. This seems to me a plausible assumption. At least, I cannot think of a nonarbitrary reason as to why this should not be the case. But if the reader disagrees, she could simply take what follows to be a conditional discussion. That is, a discussion of what would follow in regards to the permissibility of mandating neurointerventions if non-punitive measures should be constrained by the same consideration of respect as punitive measures.
} 
and what moral constraint(s) this gives rise to, most respect scholars take Kant's notion of respect as a starting point for developing their own views on respectful punishment. As is well known Kant proposed in his second formulation of the categorical imperative in the Groundworks of the Metaphysics of Morals, that in order to show the appropriate respect that the moral worth of persons require, one should always "act as to treat humanity, whether in thine own person or that of any other, in every case as an end withal, never as means only." [19, p. 50]. Central to the Kantian and neo-Kantian view of respect, is that it instructs us to recognise the inherent dignity of all persons [20]. The respect that persons are entitled qua persons is, to use Stephen Darwall's terminology, a kind of recognition respect. ${ }^{3}$ According to Darwall, to state that persons are entitled to respect in this sense, is to say "that they are entitled to have other persons take seriously and weight appropriately the fact that they are persons in deliberating about what to do.” ([21], p. 38; see also [22], p. 89-92). As is thus clear, recognition respect is accorded to a person on the basis of whether some fact(s) about her is the case; in this case whether she has the properties constitutive of a person. The respect accounts considered below have different views on what it means to give serious attention and consideration to the fact that persons qua persons are entitled to (recognition) respect and, indeed, sometimes seem to diverge with respect to what properties they take to constitute personhood. However, they all seem to endorse the ideas implied by this notion of respect, namely, first, that it cannot be forfeited by the person or otherwise lost unless the facts change, i.e. she stops being a person. Second, and perhaps more importantly, they converge on the view that respect grounds certain moral constraints on the treatment of persons. As already noted, the main interest of this paper is to examine the constraints various disrespect accounts consider there to be on state punishment, and critically discuss whether these considerations also imply that

\footnotetext{
${ }^{3}$ Recognition respect is contrasted by Darwall [21] with appraisal respect. This latter form of respect is an attitude we might have towards some persons, but not others, based on whether they show great skill as, for instance, a musician or have a strong character, and which, as such, does not ground general constraints on how members of a certain group should be treated. Furthermore, this kind of respect can be granted to a greater or lesser extent to an individual, as well as be lost or retracted if the individual fails to live up to some respect-giving standard of action or behaviour [20].
} 
obliging offenders to receive a neurointervention is in principle morally wrong. I will argue that they do not.

\section{Respecting capacities for rationality and autonomy}

The first interpretation of what characterises disrespectful and thus morally wrong modes of punishment to be considered, is one that takes disrespect to consist in curtailing offenders' capacity to be rational and autonomous. John Kleinig [23] has, for instance, proposed that being respectful in our penal practices amounts to respecting offenders' dignity. And, according to Kleinig, the foundation of this dignity is " $[t]$ he capacity to frame for oneself the choices one makes, the paths one treads, and the goals one pursues [...]” (p. 287). ${ }^{4}$ In a similar vein, Richard Lippke [24] posits that states should abstain from meting out punishment "that fails to respect the status of persons as rational beings who are capable, within limits, of making choices about the courses their lives will take.” (p. 30). Examples of punishments that would violate this constraint seem to include, inter alia, prolonged solitary confinement, drug-induced stupors, and being denied access to means of developing and expressing one's autonomy (Ibid.)..$^{5}$ There can be no doubt that certain forms of neurointerventions, e.g. interventions that render offenders minimally conscious, would indeed be disrespectful on this account. However, the relevant question for the present discussion is, of course, whether employing this account of disrespect should lead us to conclude that it would in general be wrong to mandate neurointerventions to some offenders? I believe this question should be answered dismissively.

First, mandatory neurointerventions need not target and offender capacity for rationality and autonomy. Suppose, for example, that a neurointervention was to target and alter a preference or set of

\footnotetext{
${ }^{4}$ For similar interpretations of Kleinig as defending capacity-based respect constraint on punishments, see e.g. ([37] p. 186$187)$ and ([38], p. 117).

${ }^{5}$ For the present purposes, we need not scrutinise further whether this is indeed a plausible approach to identifying disrespectful and thus morally wrong kinds of punishment, but for some persuasive arguments that it is not, see, for example, [38].
} 
preferences believed to be a key contributor to an offender's criminal behaviour, e.g. a sexual preference for children. Arguably, even if such an alteration of a preference or set of preferences lead to differences in the offender's behaviour, this would not have any effect on the offender's capacity for rationality and autonomy. To see this, suppose that I am contemplating whether to act on preference $\mathrm{X}, \mathrm{Y}$ or Z. Now, further suppose that my brain implant, for whatever reason, alters one of these desires, removes one, or adds an additional preference. In this case it seems, in my view, wrong to suggest that the intervention made by my implant has had any effect on my capacity to choose what preference to act upon. To put this point differently, it seems that at least some alterations to the content of some mental state(s) do not translate directly into an effect on the capacity to direct one's own life. ${ }^{6}$

Second, it is, at least in principle, possible that some neurointerventions could enhance rather than diminish offenders' capacity for autonomy and rationality. One might, of course, reasonably be sceptical about the possibility of enhancing offenders' autonomy. After all, there are a myriad of conceptions of autonomy on the market and, consequently, one might expect any given suggestion of how one might enhance autonomy to be controversial. However, as G. Owen Schaefer, Guy Kahane and Julian Savulescu [25] have recently pointed out, autonomy theorists seem to converge on the view that, while it is not a sufficient condition for it, the ability to reason is a necessary feature of autonomy. As they put it, the relationship between autonomy and reasoning is most often taken to be a positive one, that is, "greater reasoning, deliberation and evaluation typically leads to greater autonomy." ([25], p. 126). If, as these authors plausibly argue, this is indeed the case, then it follows that enhancing individuals' ability to reason, by, for example, biomedical means, will enhance their capacity for autonomy. One way that the use of mandatory neurointerventions might achieve this would be by removing obstacles to the exercise of this capacity. For example, in some cases they could employed to

\footnotetext{
${ }^{6}$ Jesper Ryberg [39, chapter 3] has provided a similar argument in regards to the concern that neurointerventions would necessarily have an effect on offenders' capacity for mental control.
} 
help reduce or remove the urge to act on otherwise irresistible sexual desires (see also [26]), and in other cases they might be used to reduce impulsive and aggressive behaviour (see also [27]). If, as seems plausible, some offenders' reasoning abilities are indeed impeded by the presence of strong sexual desires or other subduing impulses, then employing neurointerventions to remove, or at least reduce, the presence of them would lead to enhanced autonomy. So, what does this insight imply in regard to the view of disrespect under consideration? It implies that at least neurointerventions that improve offenders' reasoning by, for instance, reducing impediments to it, should not be considered disrespectful on this account. More precisely, because such interventions would enhance rather than curtail the offender's capacity for rationality and autonomy these interventions would not seem to qualify as being disrespectful.

In summary, a conception of disrespectful treatment of offenders as treatment that is detrimental to offenders' capacity for rationality and autonomy does not seem able to ground a general prohibition against employing mandatory neurointerventions. Specifically, while certain types of neurointerventions will indeed be ruled by this constraint, I have argued that other proposed neurointerventions would seem to have no effect on offenders' capacity for rational and autonomous decision-making. Furthermore, it was suggested that at least some interventions might even be conducive to it.

\section{Respecting offenders' prospect of reform}

The second disrespect account to be considered takes disrespect to consist of acts that are detrimental to offenders' prospect of reform. I will take Zachary Hoskins' [28] argument to this effect as representative of this view (but for a similar view see [29]). According to Hoskins, a mode of state punishment disrespects offenders: 
“[...] if it fails to respect offenders as moral persons, who as such are always capable of moral reform. Respect for offenders therefore requires, at least, that punishment not get in the way of reform. Thus I endorse as a constraint on punishment that it should not tend to undermine the prospect of offenders' reform.” ([28], p. 3).

There are two aspects of this respect account and the reform-based constraint on state punishment that flows from it that should be highlighted. First, when Hoskins suggests that offenders qua being moral persons are always capable of reforming, this should not be taken to mean that offenders are therefore inclined to do so. Rather, the idea seems to be that offenders qua being persons always have the capacity to repent and seek redemption, and this capacity for moral reform demands respect. As Kant, who Hoskins draws upon for this idea, puts it, a person "can never lose entirely his predisposition to the good." ([30], p. 256), and it is the exercise of this capacity that the institution of punishment should not get in the way of. Second, and related to the latter point, the constraint that Hoskins proposes does not make it an aim for state punishment to make offenders reform. ${ }^{7}$ Instead, the constraint more modestly proposes not punishing in a way that undermines or blocks offenders from engaging in this process. That is to say, it prescribes that a penal response should not undermine an offender's potential to come to see his criminal actions or perhaps, more generally, his moral outlook as wrong or in need of revision. Now, how might a mode of punishment violate this constraint? There are at least two ways, according to Hoskins, that state punishment might violate the reform constraint and thus disrespect offenders. First, it may inhibit or diminish offenders' capacity to "engage in the moral reflection necessary to come to see their criminal behaviour as wrong." ([28], p. 8). Second, rather than destroy or diminish offenders' capacity for moral reflection a mode of punishment might be disrespectful if it somehow diminishes an offender's motivation to engage in the process of moral reform. It should be obvious that certain modes of punishment would indeed violate the constraint in one or both of these

\footnotetext{
${ }^{7}$ For this view see, for example, Duff (2001).
} 
ways. For instance, capital punishment would seem to destroy not only offenders' capacity, but also motivation, for moral reflection ${ }^{8}$, and one can easily imagine forms of neurotechnological treatment that would do something similar, e.g. lobotomies. However, while some forms of mandatory neurointerventions would thus be impermissible to mandate, I submit that disrespecting offenders in this fashion is not a necessary feature of employing mandatory neurointerventions.

First, neurointerventions might be employed in order to make it possible or enhance the offender's capacity to engage in moral reflection. For example, although the process of coming to see one's actions as wrong surely need not always be a purely cognitive one, it seems a reasonable suggestion that sometimes moral reflection requires or is, at least, aided by one's ability to focus one's attention on the subject matter for longer periods of time. This might, however, be difficult for many offenders. For instance, studies indicate that, compared to the general population, a disproportionate number of offenders suffer from attention deficit hyperactivity disorder (ADHD). In the DSM-V, ADHD is defined as, among things, the presence of a high level of inattentiveness manifested in behaviour, e.g. an inability to sustain attention during activities and a reluctance to engage in mentally challenging activities ([31], p. 59-61). In a recent meta-analysis of 42 studies of ADHD among offenders in 15 countries, it was found that, compared to the general population, youth offenders were five times more likely (30.1\%) to have an ADHD diagnosis. Among the adult prison population the prevalence of ADHD was ten times higher than in the general population (26.2\%) [32]. Thus, if it is correct that moral reflection of the kind Hoskins has in mind requires, or is at least aided by, being able to focus one's attention, then mandating treatment for conditions that inhibits attention, such as ADHD, might improve rather than impede offenders' ability to reflect on their wrongdoing.

\footnotetext{
${ }^{8}$ At least this seem to be true if: (1) there is no afterlife, and (2) the offender has not already been reformed prior to him being killed by the state.
} 
Furthermore, and second, it may, at least in principle, be possible to administer neurointerventions to offenders who, while possessing all the necessary tools needed for engaging in the process of selfreform and perhaps even agreeing that they should engage in this process, lack the motivation to do so. For example, psychostimulants such as amphetamine and methylphenidate used to treat individuals with ADHD, have been suggested to be able to enhance the motivation of nonmedical users by, for example, making a task be more enjoyable or interesting, as well as to enhance motivation-related states such as raising the amount of energy one has available for completing the task ([33]; see also [34]). If the result of these studies turns out to be robust, then these or similar neurointerventions could perhaps be employed to enhance offenders' motivation to reform. At least this might be so in cases where the lack of motivation can be determined to be due to offenders finding the process tedious, uninteresting or lack the energy to engage in it.

In conclusion, it seems plausible that some kinds of mandated neurointerventions, i.e. neurointerventions that remedy or enhance offenders' capacity or motivation for engaging in moral reflection, do not undermine offenders' prospect of reform. Consequently, employing these interventions would not be disrespectful on this version of the respect account.

\section{Respect as opacity}

Ian Carter [35] has recently proposed that respect for persons is best understood as requiring us to “show opacity respect towards beings that meet a certain absolute standard of moral agency." (p. 554). To show opacity respect for a person involves not acting on facts about him that lie beyond those needed for establishing whether he is in possession of the basic capacities necessary for agency. Once it has been established that the person is beyond this threshold all our inquiry should cease, and the person should be treated as if opaque. Carter's investigation of opacity respect is aimed primarily at demonstrating why we have reason to ignore the fact that individuals have varying respect-giving 
capacities above a threshold when it comes to the equal distribution of goods and rights. However, by further developing the notion of opacity respect Christopher Bennett [36] has recently suggested that it has important implications in the more narrow context of criminal justice. And that one such implication is that mandating neurointerventions to some criminal offenders is (at least pro tanto) morally wrong. More precisely, as he sees it, the idea that respect requires a certain kind of epistemic abstinence coupled with his preferred view that the main purpose of criminal punishment is the communication or expression of moral criticism implies, in his words, that:

\footnotetext{
"once we have assured ourselves that an agent meets the basic conditions of liability, respect requires that we treat her, from the practical point of view, as opaque. For anything else - any attempt to ask why the person acted as they did or how they may be prevented from acting in that way in the future - would involve inquiring into differences in moral capacity [...]. ([36], p. 266).
}

As an example of a course of action by courts which is not compatible with opacity respect, Bennett points to the use of court-mandated chemical castration. On this view of respect, this practice is disrespectful because it involves acting on knowledge about offenders' mental characteristics, knowledge that should not be given any practical weight by the state in its dealings with them. Two aspects of Bennett's view are worth highlighting. First, Bennett does not take his account to imply that opacity respect rules out legal punishment as an appropriate response to wrongdoing. Indeed, an integral part of being respected as an equal is that one, qua possessing certain basic capacities for moral agency, is seen as an appropriate target for sanctions if one does not live up to the normative expectations that attach to an individual with such capacities. However, he does believe that " $[\mathrm{t}] \mathrm{he}$ argument from opacity respect suggests $[. .$.$] that sentencing should revolve around non-individualized$ responses based on the category of the offence rather than the aim of behaviour modification.” ([36], p. 
266). However, and second, Bennett also acknowledges that the benefits from mandating neurointerventions might, in some cases, be sufficiently high so as to override the requirement of opacity respect. In other words, Bennett is not claiming that it is, all things considered, morally wrong for the state to mandate neurointerventions, but rather that doing so is wrong absent defeaters. At first sight, this version of the disrespect account does seem to provide a cogent objection to employing mandatory neurointerventions in the criminal justice system. Upon further scrutiny there are, however, several challenges for this version of the disrespect account.

The first challenge concerns the moral weight of the requirement of opacity respect. Even though Bennett recognises both that respect is not the only thing of moral value, and the fact that an act shows disrespect for a person is not always a decisive reason for not performing it, he does maintain that “[c]onsiderations of respect are weighty" ([36], p. 265) and should be considered defeated only when "the consequences of failing to subject some offender to moral enhancement would be too awful." ([36], p. 256). Now, it should be noted that because Bennett's aim in his paper is to examine in detail the moral cost of not honouring the opacity requirement, he (understandingly) refrains from entering into an in-depth discussion concerning the exact location of the threshold beyond which it would be permissible to disrespect offenders by subjecting them to neurointerventions. That is to say, when the consequences of not doing so would be too awful. However, leaving this issue unresolved arguably makes it unclear whether most instances of proposed employment of mandatory neurointerventions would not in fact met this threshold. This point requires some elaboration. As Bennett himself seem to acknowledge, the well-being of individuals is surely also a weighty moral consideration. And it seems uncontroversial that the use of mandatory neurointerventions would often protect a considerable amount of this value by, for example, ensuring that an offender's potential future victims (and their families) do not come to harm, that the offender himself (and his family) will not have to suffer from the deprivation of punishment, and so on. This being so, it is, absent further argument, arguable that 
the opacity-requirement will very often have to yield for the aim of harm reduction. The point here is not that considerations of respect will never outweigh the aim of harm reduction, but rather that in most cases where the use of, for example, chemical castration or aggression-hampering drugs, would be considered to be meted out, it plausibly will not. To put it differently, presumably the main reason for even considering administering a neurointervention to an offender is that, absent the intervention, the offender will likely cause considerable harm to others or himself. But if this is true, then it at least stands to reason that in most cases where mandating neurointerventions are considered Bennett's threshold is met. Now, it is, of course, possible to deny that the consequences in such cases are sufficiently bad so as to override or outweigh the opacity requirement. But, as noted above, Bennett does not provide an argument to this effect, and it is not clear, at least to me, what such an argument would look like. However, even if such an argument is provided another challenge faces this version of the disrespect account.

Secondly, if one takes seriously the idea that the only interest courts may legitimately take in the innerlife of offenders during sentencing is whether they are in possession of basic capacities for moral agency (and thus are liable to the sanction), it has at least one unattractive implication. More precisely, it would seem to restrict us from inquiring into and, more importantly, acting to avoid unwanted psychological effects that (what most consider) morally acceptable kinds of punishment, e.g. incarceration, might have on some offenders. To see this, suppose that Alex and Ryan have both been sentenced to a year of imprisonment, and that this is the morally appropriate response to their wrongdoing. Suppose further that due to previous psychological trauma (e.g. in his childhood) Alex is at a high risk of experiencing a harmful posttraumatic stress reaction to being incarcerated. And that Ryan has a history of clinical depression and that being imprisoned is likely to lead to a relapse. Plausibly, in cases such as these where a punishment leads (or will likely lead) to harm to offenders and/or will result in additional costs to society, this particular kind of punishment should not be meted 
out. To put this point more formally: if everything else about two types of punishment $\mathrm{P}^{1}$ and $\mathrm{P}^{2}$ is equal (e.g. they equally well serve our penal purpose(s), etc.), except from the fact that $\mathrm{P}^{1}$ would cause psychological harm to a vulnerable offender while $\mathrm{P}^{2}$ would not, then it would be morally wrong to impose $\mathrm{P}^{1}$. However, the opacity constraint seems to block us from attempting to avoid imposing such a punishment, because when doing so courts would be acting on knowledge about an offender's psychology beyond that necessary for establishing whether he is liable to a sanction. If this is true, it seems to be a highly unattractive implication of the constraint. But perhaps some will find this response to be too hasty. After all, as Bennet also repeatedly points out ([36], p. 269-270, 272), consenting to someone, e.g. the state, acting on information about one's psychology is not in conflict with being shown opacity respect. On the basis of this, it might be suggested that offenders, by committing a crime, tacitly consent to the state acting on psychological information about them to avoid causing them harm of the relevant kind. Alternatively, one might argue that offenders such as Alex and Ryan with a history of psychological hardship will actively consent to such acts if consulted in order to avoid the harmful punishment. ${ }^{9}$ In both cases, so the argument might go, there is no violation of the opacity constraint because the offenders would implicitly or explicitly consent to the state acting on information about their psychology. Thus, doling out harmful punishment to psychologically vulnerable offenders could be avoided without abandoning the opacity constraint. In my view, however, neither of these suggestions are persuasive. First, more needs to be said about the scope of the tacit consent presumably granted by offenders when engaging in criminal activities in order for it to rule out the use of mandatory neurointerventions. That is, an argument is needed for why it should not

\footnotetext{
${ }^{9}$ It is worth noting that strictly speaking arguing in either of these manners seems to imply that the central issue regarding violations of the opacity constraint is whether a given offender consents to information about his mental capacities being employed by the courts and not whether the neurointervention is mandated by a court. To put it differently, it is conceivable that some offenders will consent to courts using and acting on their psychological information while others will not. And so, in the former cases no violation of the opacity constraint will have taken place if the state obliges an offender to receive a neurointervention, while a violation of the constraint would take place if the same was to happen to the latter group of offenders. What this shows is that the opacity constraint might in fact not rule out the use of mandatory neurointerventions per se, but rather the imposition of involuntary neurointerventions. I will, however, not pursue this issue further here.
} 
be taken to extend beyond the specific harm reduction purpose under consideration; if it is the case that an offender when committing a crime tacitly consents to the state acting on psychological information about him to avoid harming him, why does it not allow the state to employ such information to reduce the risk of having to punish the offender again in the future by employing a neurointervention? It is not clear, at least to me, what argument could be provided in order to restrict the scope of the tacit consent in a way that would rule this out. Second, while the question of whether psychologically vulnerable offenders will indeed consent to the state acting on information about their psychological history is ultimately an empirical one, it seems plausible that many (or perhaps most) will. However, it surely also seems plausible that at least some offenders will refuse to do so because, for example, they do not trust the state to only use the information for this benign purpose. If this is true, then it would seem to follow that, at least in these cases, the state cannot avoid harming psychologically vulnerable offenders without violating the opacity constraint. ${ }^{10}$ It might, of course, be denied that the moral import of the harm to these ex hypothesi few offenders is sufficient to override the requirement of opacity. But, as also noted above, it is not clear what argument might be provided to sustain this view.

Turning now to the third challenge for the opacity constraint it seems that even if it is accepted that offenders should be treated as if opaque this does not rule out the use of mandatory neurointerventions, or at least so I will now argue. As briefly mentioned above, Bennett [36] maintains that the opacity requirement implies that sentences should be non-individualised and be based on what type of offence the offender has committed. Supposedly, the reason for restricting sentencing in this way is that this will ensure that, inter alia, the specific motivations that the offender had for offending will remain for all practical purposes opaque. That is to say, the state's response to the offender's

\footnotetext{
${ }^{10}$ An interesting objection that I will not discuss at length here as it would take us too far astray, is that because the offender has refused to let the state act on information about his psychological history to avoid harming him, he is himself (at least partly) responsible for the harm that befalls him when he, for instance, develops PTSD or relapses into depression. Thus, the state would do no wrong if a punishment was harmful in the relevant sense.
} 
wrongdoing will be based solely on facts that are external to him, i.e. his behaviour. However, could not mandated neurointerventions in fact be such a non-individualised response to specific forms of wrongdoing? Suppose, as an example, that an effective and safe aggression-hampering neurointervention, which ensured that the recipients of it would be no more and no less aggressive than the average person, were administered to all individuals convicted of causing serious bodily harm to others. Now, because the neurointervention is mandated to every offender whose wrongdoing falls in the aforementioned category, it would seem that there would be no violation of the opacity constraint. That is, such use of the neurointervention would be non-individualised and based solely on the fact that the offender's offence was of a certain kind. If this is true, then the more general point to be drawn from this is that given the appropriate scheme for mandating neurointervention, i.e. one where every offender whose offence falls in a certain category is subjected to an intervention, this account of disrespect will allow for such treatment.

In summary, I have in this section argued that a version of the respect account in which respect is conceived as requiring us to treat offenders as if opaque, does not persuasively rule out the use of mandatory neurointerventions in the criminal justice system. I offered three arguments to this effect. First, absent further argument it is arguable that the moral weight of the opacity constraint is insufficient to block most use of mandatory neurointerventions employed in the service of harm reduction. Second, by instructing us to not act on knowledge about the psychological make-up of offenders the account has an unattractive implication. And third, it was argued that a scheme could in principle be devised which would avoid the concerns expressed by proponents of this account.

\section{Conclusion}

In this paper, I have argued that three plausible respect-based objections against the use of mandatory neurointerventions in the criminal justice system are unpersuasive. Firstly, I argued that showing 
respect for offenders' capacity for rationality and autonomy is unable to ground a general moral prohibition of such interventions, because some neurointerventions would have no effect on this capacity and, indeed, some interventions could be conducive to it. Secondly, it was argued that since some mandatory neurointerventions could plausibly aid rather than impede offenders' prospect of reform, this version of the concern also fails to rule out their use. Third, and finally, I have argued that respect conceived as a demand for opacity does not convincingly rule out the use of mandatory neurointerventions. These conclusions do not, however, suffice to show that a practice of mandating neurointerventions to offenders is morally permissible. First, and as noted in the introduction, there may be other ethical concerns that will rule out their use. And second, other conceptions of what constitutes disrespectful punishment might evade the challenges I have outlined above. ${ }^{11}$ What I do hope to have shown, however, is that, at least on the interpretations of the concern considered, respect for offenders is not incompatible with mandating some forms of neurointerventions.

\section{References}

1. Busto, Elena del, and Michael C Harlow. 2011. American Sexual Offender Castration Treatment and Legislation. In International Perspectives on the Assessment and Treatment of Sexual Offenders: Theory, Practice, and Research, ed. Douglas P. Boer, Reinhard Eher, Leam A. Craig, Michael H. Miner, and Friedemann Pfäfflin, 543-571. UK: Wiley-Blackwell.

2. Hough, Mike, Anna Clancy, Tim McSweeney, and Paul J Turnbull. 2003. The impact of Drug Treatment and Testing Orders on offending: two-year reconviction results. London: The Home Office, Research, Development and Statistics Directorate.

3. Chew, Christopher, Thomas Douglas, and Nadira S. Faber. 2018. Biological Interventions For

\footnotetext{
${ }^{11}$ One interesting way one could do so may, for example, be to explore further whether respect requires that modes of punishment do not pose a symbolic threat to offenders' agency, and whether such a constraint is violated by mandatory neurointerventions (see e.g. [41]).
} 
Crime Prevention. In Treatment for Crime: Philosophical Essays on Neurointerventions in Criminal Justice, ed. David Birks and Thomas Douglas. Oxford, United Kingdom: Oxford University Press.

4. Berman, Mitchell E., Michael S. McCloskey, Jennifer R. Fanning, Julie A. Schumacher, and Emil F. Coccaro. 2009. Serotonin Augmentation Reduces Response to Attack in Aggressive Individuals. Psychological Science 20: 714-720.

5. Duke, Aaron A., Laurent Bègue, Rob Bell, and Tory Eisenlohr-Moul. 2013. Revisiting the Serotonin-Agression Relation in Humans: A Meta-Analysis. Psychological Bulletin 139.

6. Young, L, J A Camprodon, M Hauser, A Pascual-Leone, and R Saxe. 2010. Disruption of the right temporoparietal junction with transcranial magnetic stimulation reduces the role of beliefs in moral judgments. Proc Natl Acad Sci U S A 107: 6753-6758. doi:10.1073/pnas.0914826107.

7. Tassy, Sébastien, Olivier Oullier, Yann Duclos, Olivier Coulon, Julien Mancini, Christine Deruelle, Sharam Attarian, Olivier Felician, and Bruno Wicker. 2012. Disrupting the right prefrontal cortex alters moral judgement. Social Cognitive and Affective Neuroscience 7: 282-288. doi:10.1093/scan/nsr008.

8. Dambacher, Franziska, Teresa Schuhmann, Jill Lobbestael, Arnoud Arntz, Suzanne Brugman, and Alexander T. Sack. 2015. Reducing proactive aggression through non-invasive brain stimulation. Social Cognitive and Affective Neuroscience 10: 1303-1309. doi:10.1093/scan/nsv018.

9. Molero-Chamizo, Andrés, Raquel Martín Riquel, Juan Antonio Moriana, Michael A. Nitsche, and Guadalupe N. Rivera-Urbina. 2019. Bilateral Prefrontal Cortex Anodal tDCS Effects on Self-reported Aggressiveness in Imprisoned Violent Offenders. Neuroscience 397: 31-40. doi:10.1016/j.neuroscience.2018.11.018.

10. Lu, Lin, Xi Wang, and Thomas R Kosten. 2009. Stereotactic Neurosurgical Treatment of Drug Addiction. The American Journal of Drug and Alcohol Abuse 35: 391-393. doi:10.3109/00952990903312478.

11. Newton, Alexander, Xennor May, Steven Eames, and Maryam Ahmad. 2019. Economic and social 
costs of reoffending. Ministry of Justice.

12. Douglas, Thomas. 2014. Criminal Rehabilitation Through Medical Intervention: Moral Liability and the Right to Bodily Integrity. The journal of ethics 18: 101-122. doi:10.1007/s10892-014-91616.

13. Shaw, Elizabeth. 2016. The Right to Bodily Integrity and the Rehabilitation of Offenders Through Medical Interventions: A Reply to Thomas Douglas. Neuroethics https://do.

14. Douglas, Thomas. 2016. Nonconsensual Neurocorrectives and Bodily Integrity: a Reply to Shaw and Barn. Neuroethics. Neuroethics. doi:10.1007/s12152-016-9275-6.

15. Bublitz, Jan Christoph, and Reinhard Merkel. 2014. Crimes Against Minds: On Mental Manipulations, Harms and a Human Right to Mental Self-Determination. Criminal Law and Philosophy 8: 51-77. doi:10.1007/s11572-012-9172-y.

16. Craig, Jared N. 2016. Incarceration, Direct Brain Intervention, and the Right to Mental Integrity - a Reply to Thomas Douglas. Neuroetbics 9. Neuroethics: 107-118. doi:10.1007/s12152-016$9255-x$.

17. Petersen, Thomas Søbirk, and Kristian Kragh. 2017. Should violent offenders be forced to undergo neurotechnological treatment? A critical discussion of the "freedom of thought" objection. Journal of Medical Ethics 43: 1-5. doi:10.1136/medethics-2016-103492.

18. Dillon, Robin S. 2018. Respect. Stanford Encyclopedia of Philosophy. doi:10.1111/1467-9973.00225.

19. Kant, Immanuel. 2019. Groundwork of the Metaphysics of Morals. Compass Circle.

20. Woodruff, Paul Bestor. 2019. Respect. In International Encyclopedia of Ethics, ed. Hugh LaFollette. John Wiley \& Sons, Ltd.

21. L. Darwall, Stephen. 1977. Two Kinds of Respect. Ethics 88: 36-49.

22. E. Hill, Thomas. 2000. Respect, Pluralism, and Justice - Kantian Perspectives. New York: Oxford University Press.

23. Kleinig, John. 1998. The Hardness of Hard Treatment. In Fundamentals of Sentencing Theory, ed. 
Andrew Ashworth and Martin Wasik. New York: Oxford University Press.

24. Lippke, Richard L. 1998. Arguing against inhumane and degrading punishment. Criminal Justice Ethics 17: 29-41.

25. Schaefer, G. Owen, Guy Kahane, and Julian Savulescu. 2014. Autonomy and enhancement. Neuroethics 7: 123-136. doi:10.1007/s12152-013-9189-5.

26. Douglas, Thomas, Pieter Bonte, Farah Focquaert, Katrien Devolder, and Sigrid Sterckx. 2013. Coercion, Incarceration, and Chemical Castration: An Argument From Autonomy. Journal of Bioethical Inquiry 10: 393-405. doi:10.1007/s11673-013-9465-4.

27. Ryberg, Jesper. 2012. Punishment, Pharmacological Treatment, and Early Release. International Journal of Applied Philosopby 26: 231-244. doi:10.5840/ijap201226217.

28. Hoskins, Zachary. 2013. Punishment, contempt, and the prospect of moral reform. Criminal Justice Ethics 32: 1-18. doi:10.1080/0731129X.2013.777250.

29. Hampton, J. 1984. The Moral Education Theory of Punishment. Pbilosophy \& Public Affairs 13: $208-238$.

30. Kant, Immanuel. 1991. The Metaphysics of Morals. Cambridge: Cambridge University Press.

31. APA. 2013. Diagnostic and Statistical Manual of Mental Disorders. Fifth Edit. Arlington, VA: American Psychiatric Association.

32. Young, S., D. Moss, O. Sedgwick, M. Fridman, and P. Hodgkins. 2015. A meta-Analysis of the prevalence of attention deficit hyperactivity disorder in incarcerated populations. Psychological Medicine 45: 247-258. doi:10.1017/S0033291714000762.

33. Ilieva, Irena P., and Martha J. Farah. 2013. Enhancement stimulants: perceived motivational and cognitive advantages. Frontiers in Neuroscience 7: 1-6. doi:10.3389/fnins.2013.00198.

34. Vrecko, Scott. 2013. Just How Cognitive Is "Cognitive Enhancement"? On the Significance of Emotions in University Students' Experiences with Study Drugs. AJOB Neuroscience 4: 4-12. doi:10.1080/21507740.2012.740141. 
35. Carter, Ian. 2011. Respect and the Basis of Equality. Ethics 121: 538-571.

36. Bennett, Christopher. 2018. Intrusive Intervention and Opacity Respect. In Treatment for Crime: Philosophical Essays on Neurointerventions in Criminal Justice, ed. David Birks and Thomas Douglas, 255-273. Oxford, United Kingdom: Oxford University Press.

37. Ryberg, Jesper. 2018. Neuroscientific Treatment of Criminals and Penal Theory. In Treatment for Crime: Philosophical Essays on Neurointerventions in Criminal Justice, ed. David Birks and Thomas Douglas. Oxford: Oxford University Press.

38. Petersen, Thomas S. 2010. Punishment and Dignity. In Punishment and Ethics: New Perspectives, ed. Jesper Ryberg and J. Angelo Corlett. Palgrave Macmillan.

39. Ryberg, Jesper. 2019. Neurointerventions, Crime, and Punishment: Ethical Considerations. New York: Oxford University Press.

40. Duff, R A. 2001. Punishment, Communication and Community. Oxford: Oxford University Press.

41. Shaw, Elizabeth. 2018. Against the Mandatory Use of Neurointerventions. In Treatment for Crime: Philosophical Essays on Neurointerventions in Criminal Justice, ed. David Birks and Thomas Douglas. Oxford, United Kingdom: Open University Press. 